\title{
PELATIHAN PEMBUATAN AKSESORIS DARI LIMBAH KAIN PERCA OLEH IBU-IBU RUMAH TANGGA DESA BLIMBINGAN BATURAN
}

\author{
Diana Dewi Wahyuningsih, Ninda Beny Asfuri \\ Universitas Tunas Pembangunan Surakarta, Indonesia \\ dianadewibagus@gmail.com
}

\begin{abstract}
The village of Blimbingan is one of the villages in Baturan village, Colomadu District, Karanganyar Regency. The Housewives of the village Blimbingan actually have the skill of sewing but the potential they have is not developed. There are 5 handyman in Blimbingan village so that many of the patchwork fabric that should be used. Patchwork fabric in Blimbingan village is more often discarded and burned so it pollutes the environment of the surrounding community especially air pollution, and also many still good batik patchwork that should still be utilized to be processed into goods that have a high economic value. The majority of the community of Blimbingan Village are less concerned about environmental issues, they do not know the benefits that will be gained if they are able to utilize patchwork, their view of not the importance of a supposed patchwork cloth should be changed so that they should be adapted by being given socialization and counseling. This community service aims to provide socialization as well as training on making accessories by utilizing patchwork waste in Blimbingan village as well as providing guidance to develop into a productive economic business in order to become a new opportunity for the group of Mothers-Housewives village Blimbingan. The methods used in this activity are by counseling, training, monitoring and mentoring. This community devotion activity is a partner of motherhousewife Group has effectively understood the utilization of waste patchwork for beneficial products such as the manufacture of accessories and many people in need. Knowledge and skills of partners increased by $98 \%$, which was marked by the success of making accessories products.

Keywords: Accessories, Waste patchwork
\end{abstract}

\begin{abstract}
Abstrak
Desa Blimbingan merupakan salah satu desa di Kelurahan Baturan, Kecamatan Colomadu, Kabupaten Karanganyar. Ibu-ibu rumah tangga desa Blimbingan sebenarnya memiliki ketrampilan yaitu menjahit tetapi potensi yang mereka miliki tidak dikembangkan. Ada 5 tukang jahit di Desa Blimbingan sehingga banyak sisa kain perca yang seharusnya bisa dimanfaatkan. Kain perca yang ada di Desa Blimbingan lebih sering dibuang dan dibakar sehingga mencemari lingkungan masyarakat sekitar terutama pencemaran udara, dan juga banyak perca-perca batik yang masih bagus yang seharusnya masih bisa dimanfaatkan untuk diolah menjadi barang yang mempunyai nilai ekonomis tinggi. Sebagian besar masyarakat Desa Blimbingan kurang peduli terhadap permasalahan lingkungan, mereka tidak mengetahui manfaat yang akan didapat jika mereka mampu memanfaatkan kain perca, pandangan mereka mengenai tidak pentingnya kain perca yang seharusnya dibuang itu seharusnya diubah sehingga mereka harus disadarkan dengan diberi sosialisasi serta penyuluhan. Kegiatan Pengabdian masyarakat ini bertujuan memberikan sosialisasi serta pelatihan pembuatan aksesoris dengan memanfaatkan limbah kain perca di Desa Blimbingan serta memberikan bimbingan untuk mengembangkan menjadi usaha ekonomi produktif agar bisa menjadi peluang kerja baru bagi kelompok ibu-ibu rumah tangga Desa Blimbingan. Metode yang digunakan dalam kegiatan ini adalah dengan penyuluhan, pelatihan, monitoring dan pendampingan. Simpulan Kegiatan Pengabdian masyarakat ini yaitu mitra kelompok ibu-ibu rumah tangga telah secara efektif memahami pemanfaatan limbah kain perca untuk produk yang bermanfaat seperti pembuatan aksesoris dan banyak masyarakat yang membutuhkan. Pengetahuan dan ketrampilan mitra meningkat $98 \%$ yang ditengarai dengan berhasilnya dengan baik pembuatan produk aksesoris.
\end{abstract}

Kata Kunci: Aksesoris, Limbah kain perca 


\section{Pendahuluan}

Ibu-ibu rumah tangga Desa Blimbingan sebenarnya memiliki ketrampilan yaitu menjahit tetapi potensi yang mereka miliki tidak dikembangkan. Ada 5 tukang jahit di Desa Blimbingan Baturan sehingga banyak sisa kain perca, tetapi warga Desa Blimbingan tidak mengetahui akan manfaat kain perca. Kain perca lebih sering dibuang dan dibakar sehingga mencemari lingkungan masyarakat sekitar terutama pencemaran udara, dan juga banyak perca-perca batik yang masih bagus yang seharusnya masih bisa dimanfaatkan untuk diolah menjadi barang bernilai tinggi. Kebiasaan masyarakat yang kurang baik, yaitu membakar kain perca kurang dipahami oleh masyarakat Desa Blimbingan yang bekerja sebagai tukang jahit. Sebagian besar masyarakat Desa Blimbingan kurang peduli terhadap permasalahan lingkungan, mereka tidak mengetahui manfaat yang akan didapat jika mereka mampu memanfaatkan kain perca, pandangan mereka mengenai tidak pentingnya kain perca yang seharusnya bisa dimanfaatkan malah dibuang itu seharusnya diubah sehingga mereka harus disadarkan dengan diberi sosialisasi serta penyuluhan. Mereka yang bersikap tidak peduli dipengaruhi faktor pendidikan yang rendah mengingat masyarakat Desa Blimbingan yang sebagian besar hanya lulusan Sekolah Dasar dan Sekolah Menengah.

Dari hasil wawancara serta pengamatan, kelompok ibu-ibu rumah tangga Desa Blimbingan berkeinginan untuk memiliki mata pencarian untuk mendapat tambahan penghasilan sehingga bisa membantu suami dalam mencukupi kebutuhan rumah tangga dan setidaknya mempunyai kegiatan yang positif tetapi menguntungkan. Setelah mengkaji potensi yang ada di wilayah tersebut disepakati untuk memberikan ketrampilan bagi ibu-ibu rumah tangga yang menganggur setelah selesai dengan urusan rumahnya, yaitu pelatihan berupa membuat aksesoris dari limbah kain perca serta memberi arahan dalam memasarkannya. Karena banyaknya limbah kain perca dari penjahit di Desa Blimbingan yang hanya dibuang dan dibakar sehingga tim PKMS memutuskan untuk menjadikan limbah kain perca yang tadinya tidak mempunyai nilai ekonomis menjadi barang yang mempunyai nilai ekonomis tinggi. Tim PKMS berusaha memberikan penjelasan mengenai pemanfaatan limbah kain perca yang bisa disulap menjadi barang yang mempunyai nilai ekonomis tinggi sehingga menarik masyarakat yang suka fashion seperti kalung, bros, jepit rambut, bando, ikat rambut. Tim PKMS juga ingin memberikan bekal pelatihan kepada kelompk ibu-ibu rumah tangga dalam hal pembuatan aksesoris, yang mana bekal ketrampilan ini nantinya dapat dijadikan modal wirausaha bagi ibu-ibu rumah tangga maupun sebagai usaha pioneer yang akan bisa menjadi tonggak berdirinya usaha-usaha baru yang sejenis. Keunggulan pembuatan aksesoris dari kain perca adalah modal yang dikeluarkan cukup sedikit. Kegiatan pembuatan aksesoris dari kain perca akan dikembangkan menjadi usaha ekonomi produktif yang pemasarannya bisa menjangkau sampai ke luar desa dengan memanfaatkan media sosial seperti instagram, facebook, blog, shopee dan dititipkan ke penjual aksesoris sehingga akan menjadi peluang kerja baru di Desa Blimbingan dan bisa membuka lapangan usaha bagi warga yang belum mempunyai pekerjaan terutama ibu-ibu.

Permasalahan Mitra yang ada di kelompok Ibu-Ibu Rumah Tangga Desa Blimbingan Baturan antara lain : 1) Limbah kain perca dalam jumlah besar belum dimanfaatkan dan hanya dibuang, menimbulkan pencemaran lingkungan, 2) Ibu-ibu 
banyak yang tidak bekerja dan hanya sebagai ibu rumah tangga sehingga banyak memiliki waktu luang 3) Belum ada upaya bimbingan untuk memanfaatkan limbah kain perca di Desa Blimbingan, Baturan menjadi bahan yang berguna dan bernilai ekonomi.

\section{Metode}

Khalayak sasaran yang terlibat dalam pelatihan ini semuanya ibu-ibu rumah tangga yang berusia antara 27 tahun sampai dengan 50 tahun. Kegiatan sosialisasi dan pelatihan pembuatan aksesoris seperti kalung, bros dan bando dari kain perca sudah terlaksana yang diikuti oleh ibu-ibu rumah tangga desa Blimbingan, Baturan. Berdasarkan analisis situasi dan permasalahan yang dihadapi oleh mitra kelompok ibu- ibu rumah tangga di Desa Blimbingan, Baturan maka Tim PKMS memberikan solusi yang memungkinkan dan bisa dilaksanakan oleh anggota kelompok ibu-ibu rumah tangga yaitu dengan metode: 1) Memberikan penyuluhan untuk meningkatkan pengetahuan dan pemahaman ibu rumah tangga mengenai limbah kain perca yang bisa dimanfaatkan untuk pembuatan berbagai aksesoris, 2) Mengadakan pelatihan pembuatan aksesoris dengan memanfaatkan limbah yang melimpah di desa (limbah kain perca) dan peserta memperhatikan cara pembuatan, 3) Tim PKMS memberikan pendampingan dan kelompok ibu-ibu rumah tangga membuat aksesoris dari limbah kain perca secara mandiri, 4) Memberikan bimbingan usaha penjualan aksesoris (proses pembuatan sampai pengemasan, pemasaran, manajemen usaha) agar bisa menjadi peluang usaha baru di desa.

Materi dan pratek yang diajarkan meliputi pembuatan bando, pembuatan kalung, pembuatan bros dan cekip, Ikat rambut cantik serta praktek pengemasan. Untuk kalung sebelum dikemas sebaiknya disetrika terlebih dahulu bagian ikatnya agar rapi, Untuk pengemasan Siapkan plastik dengan ukuran yang agak besar sedikit dari produk aksesoris agar bagian atas agak longgar sehingga bagian atas bisa diberi kertas label lalu di streples sehingga produk menjadi menarik.

Partisipasi Mitra dalam pelaksanaan Program yaitu ikut berperan pada penentuan tanggal pelaksanaan, ikut berperan pada kegiatan penyuluhan, pelatihan, pengemasan dan pemasaran. Evaluasi pelaksanaan program dilaksanakan dua kali yaitu sebelum dan sesudah pelaksanaan. Hal ini untuk melihat adanya peningkatan ketrampilan bagi khalayak sasaran.

\section{Hasil dan Pembahasan}

Kegiatan pelatihan pembuatan aksesoris dari kain perca dimulai dengan pencarian alat dan bahan-bahan yang menunjang untuk pelaksanaan PKMS, jadi semua bahan yang diperlukan dicari terlebih dahulu. Kain-kain perca dari penjahit juga dikumpulkan jadi satu dirumah ibu RT yang sekaligus digunakan untuk acara pelatihan pengabdian.

Penyuluhan dilaksanakan dirumah salah seorang khalayak sasaran yaitu Ibu RT. Penyuluhan diikuti 10 orang kelompok Ibu-Ibu Rumah Tangga. Acara penyuluhan dimulai dengan sambutan oleh ketua RT. Pada kegiatan ini juga melibatkan mahasiswa Fakultas Keguruan dan Ilmu Pendidikan Universitas Tunas Pembangunan Surakarta.

Setelah sambutan selesai, paparan berisi materi oleh pembicara utama Diana Dewi Wahyuningsih, M.Pd. Materi meliputi pemanfaatan kain perca menjadi barang bernilai guna dan bernilai ekonomis tinggi Setelah pemberian materi selesai, dilanjutkan dengan 
sesi Tanya jawab antara dosen dengan peserta. Pertanyaan dari khalayak sasaran berkisar tentang cara pembuatan dan alat dan bahan tambahan yang digunakan untuk pembuatan aksesoris. Untuk praktek pembuatan aksesoris dibimbing oleh Dosen PGSD yaitu Ibu Ninda Beny Asfuri.

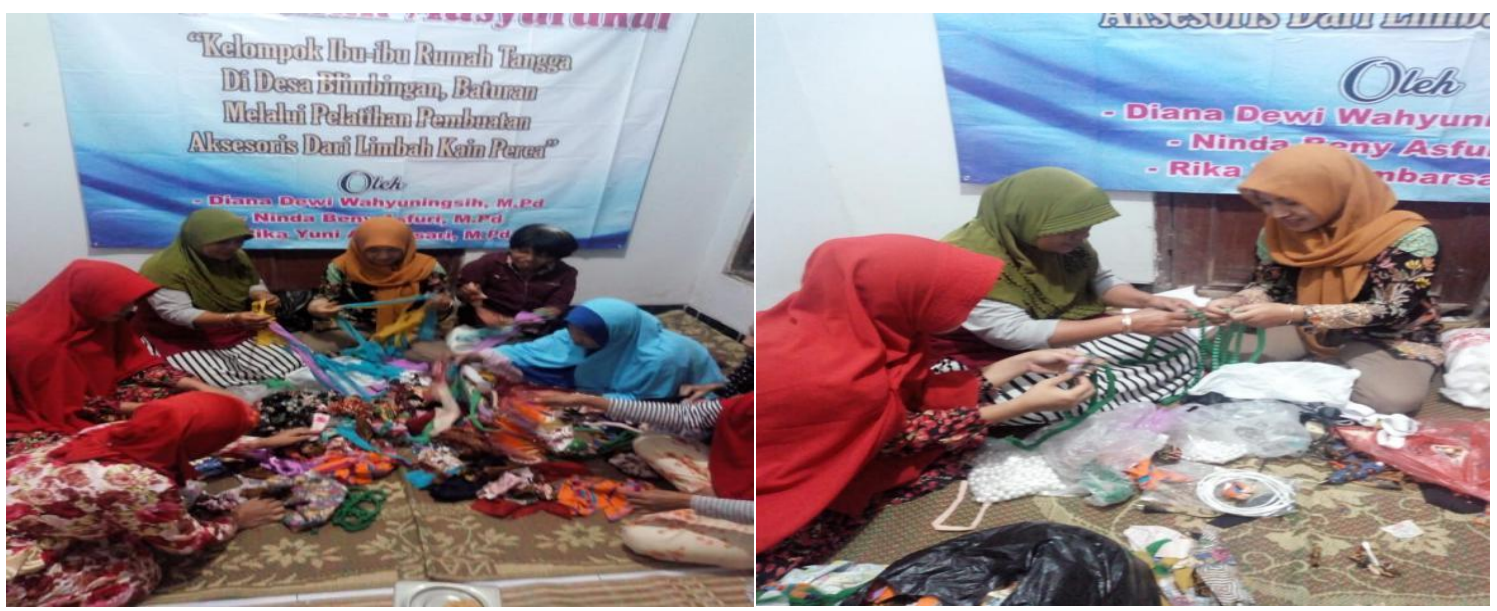

Gambar 1. Peserta mencoba membuat kalung dengan diarahkan tim PKMS

Pembuatan aksesoris dapat menjadi salah satu alternatif yang tepat dalam mengatasi permasalahan tersebut karena fungsinya yang dapat memberikan tambahan penghasilan bagi ibu-ibu rumah tangga di desa blimbingan Rt 02/ IV Baturan disamping itu juga bisa untuk mempercantik/ menunjang penampilan pribadi tanpa harus membeli, sehingga modal dasar yang diperlukan yaitu wawasan dan ketrampilan ibu rumah tangga sudah meningkat sehingga apabila mereka ingin menggunakan secara pribadi mereka tingga membuat dan juga bisa memasarkan produk yang dibuat dengan cara yang telah diajarkan seperti lewat media sosial.

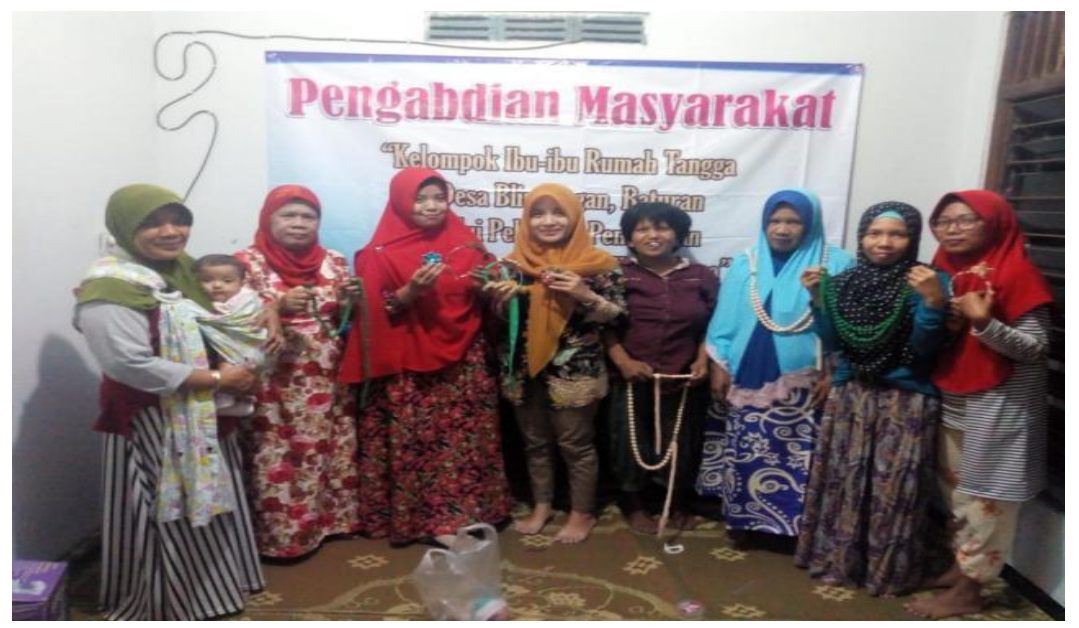

Gambar 2. Peserta merasa senang setelah beberapa pertemuan akhirnya mereka bisa membuat berbagai aksesoris

Tingkat partisipasi khalayak sasaran yang terlibat dalam kegiatan ini sangat baik terbukti banyaknya pertanyaan saat diadakan sesi diskusi setelah tim PKMS menjelaskan materi dan juga saat pelatihan peserta tampak serius mengikuti dan menirukan tahap demi tahap saat membuat aksesoris walaupun kadang banyak kesulitan yang dihadapi 
para peserta dalam membuat aksesoris tetapi para peserta tidak segan untuk bertanya dan mereka tidak mudah putus asa sehingga pada akhirnya para peserta berhasil dalam membuat aksesoris. Ada juga 1 peserta yang kreatif mencoba-coba membuat desain sendiri dan langsung ditularkan ke peserta lainnya sehingga dari sini semua saling belajar. Dengan antusias yang tinggi membuat tim PKMS merasa senang.

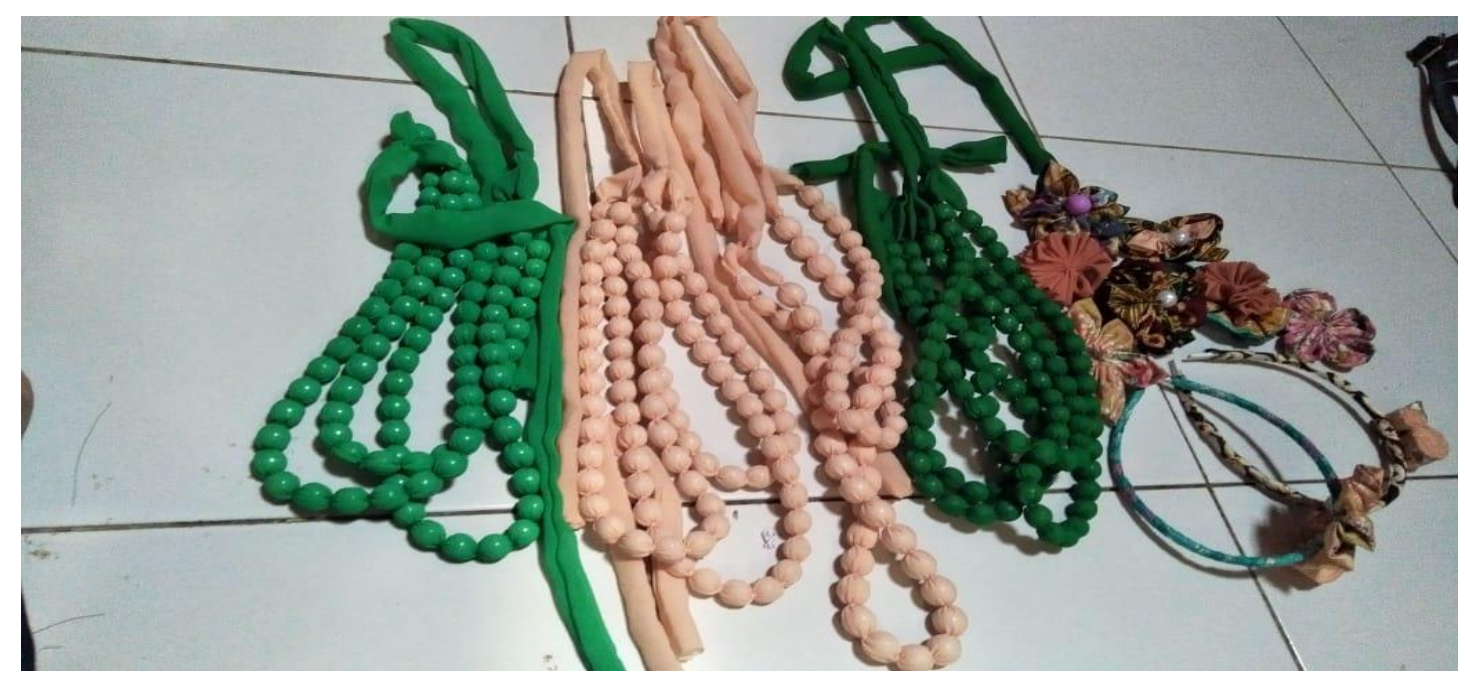

Gambar 3. Aneka aksesoris yang dibuat ibu-ibu seperti kalung, bros dan bando

\section{Kesimpulan}

Penyuluhan tentang pemanfaatan kain perca menjadi aksesoris dan produksi bros, bando, kalung, cekip, ikat rambut dapat dikatakan berhasil terbukti banyaknya pertanyaan yang dilontarkan ibu-ibu rumah tangga saat penyuluhan. Pada saat praktek kelompok ibu-ibu rumah tangga bergotongroyong dalam pembuatan aksesoris yang telah diajarkan. Mitra yaitu kelompok ibu-ibu rumah tangga telah secara efektif memahami pemanfaatan limbah kain perca untuk produk yang bermanfaat seperti pembuatan aksesoris dan banyak masyarakat yang membutuhkan. Pengetahuan dan ketrampilan mitra meningkat yang ditengarai dengan berhasilnya dengan baik pembuatan produk aksesoris.

\section{Daftar Pustaka}

Anggraini, Sri. (2015). Pemanfaatan Limbah Kain Perca Untuk Industri Rumah Tangga. Seminar Nasional Pengabdian Kepada Masyarakat.

Sulistyaningsih, Dwi, dkk. (2017). Produk Kerajinan Tangan Dari Limbah Kain Perca Bagi Ibu- Ibu Rumah Tangga. Prosiding Implementasi Penelitian Pada Pengabdian Menuju Masyarakat Mandiri Berkemajuan 